\title{
The Hypothesis of Hyperia from the Perspective of Neuronal Plasticity
}

\author{
Javier Álvarez-Rodríguez \\ Servicio de Psiquiatría, Complejo Asistencial Universitario de León, León, Spain \\ Email: jar1950@hotmail.com
}

Received 23 December 2015; accepted 24 January 2016; published 27 January 2016

Copyright (C) 2016 by author and Scientific Research Publishing Inc.

This work is licensed under the Creative Commons Attribution International License (CC BY). http://creativecommons.org/licenses/by/4.0/

c) (i) Open Access

\begin{abstract}
We analyze certain mental automatisms appearing in the consciousness with phenomenological features of simple partial seizures (SPSs). We propose to include all these phenomena into a cognitive function to which we term hyperia. In this paper, we analyze the similarities between the nature of this cognitive function and the mechanisms used by our brain to elicit neuronal plasticity.
\end{abstract}

\section{Keywords}

Bipolar Disorder, Glutamate, Partial Seizures, RDoC, Repetition, Reflex Epilepsies, Schizophrenia

\section{Introduction}

Based on still valid writings of renowned neuroscientists of the past century [1] [2], we have been researching for years on a group of psychic phenomena that so far constituted a grey area between Psychiatry and Neurology, diagnosed as epileptic fits when a congruent electroencephalogram (EEG) confirming the neuronal discharge has been recorded, and more frequently as symptoms of different psychiatric disorders [3]. These psychic experiences appear always in the same way: suddenly the attention focuses completely on the sole experience occurring at this moment on the mind, a phenomenon that Henri Ey denominates "narrowing of consciousness" ([2], p. 542). Such experiences present always the next phenomenological characteristics: distortion of experienced inner time, automatic nature, great intensity, and strong feeling of strangeness [4]. Recently, we proposed to term them Hipersyncronic Mental Automatisms (HMAs) [5].

The best way to understand these experiences is by means of an example of a HMA which occurs so frequent among normal people that many of us will surely have experienced it. We are referring to déjà vu, "a paroxysmal feeling of familiarity which can be found in no less than half the normal population, but which just as easily can be conceived as a partial seizure” ([6], p. 103). Well, this paramnesia contains the five features which we have just described as defining a HMA. 
Psychiatric practice recognizes a great variety of psychic phenomena with these clinical characteristics:

1) Hallucinations or false perceptions that impose themselves on the consciousness with undeniable conviction of truth;

2) Primary delusional ideas [7], where a sudden though imposes itself on one's awareness with such force that it gives the impression of irrefutable certainty;

3) Crises of depersonalization: the subject suddenly has the vivid impression of observing himself as wholly or partially different from normal, despite knowing that the sense organs are working properly;

4) Derealization: now it is the environment which is perceived as distorted;

5) Panic attack, that is, an acute assault of anguish and terror taking over the consciousness with such sudden intensity that the subject has the impression when he is losing the control of his mind;

6) Sadness attack: here the unexpected experience consists in a sudden psychic pain invading the awareness completely and for no apparent reason, the sorrow being inexplicable for the subject suffering it;

7) Joy attack: a state of intense bliss with no apparent cause, which takes over consciousness passively;

8) Alternative acute attacks of these two opposite affective experiences that mimic a quick cycling bipolar disorder.

At a first step, we proposed that HMAs should be diagnosed as simple partial seizures (SPSs), but after having carried out numerous bibliographical researches to look for the true nature of these experiences, we found two kinds of arguments in favor of the physiological origin of these epileptiform productions:

1) These psychic automatisms are present in the majority of the most outstanding creations of humanity, without their authors conferring them some pathological value. Indeed, we found these HMAs in the writings of Christian mystics such as Paul of Tarsus, Augustine of Hippona of Hippo, Hildegard of Bingen, John Tauler, Henry Suso, Angela of Foligno, etc. But, surprisingly they are also present in the original works of many other non-religious creators such as philosophers Plotinus, Pascal, Nietzsche; painters like William Blake, Van Gogh, Salvador Dalí; novelists such as Dostoyevsky, Marcel Proust, Hermann Hesse; poets like Walt Whitman, Rabindranath Tagore, and Juan Ramón Jiménez, etc.

2) On the other hand, the study of epilepsies provided us new evidences about the physiological nature of some epileptic activities:

a) The existence of reflex epilepsies [8], that is, epileptic seizures triggered by certain stimuli, so much simple stimuli (a repetitive flashing light, a rhythmic sound, hot water, etc.) as complex ones (certain harmonic musical pieces, pronunciation or evocation of a word with strong emotional charge, etc.). Generally reflex epilepsies are due to repetitive stimuli that because of the reiterative character become determining an epileptic discharge. Well, we all have experienced some kinds of reflex epilepsies such as certain musicogenic and affective epilepsies, a fact suggesting the physiological nature of such epileptiform activities [9]-[11].

b) The existence of cerebral areas, especially prefrontal cortex, entorhrinal cortex dentate gyrus, and more remarkably hippocampus and amygdala, in which these epileptogenic discharges appear in an apparently spontaneous and physiological way, and furthermore associated to processes not only physiological but also indispensable to the survival of the individual and the species, such as learning [12] and sexuality [13] [14].

c) The discovery of two complementary and opposed epileptiform activities to which Wilson and Bragdon refer in the next terms:

These data suggest a possible new principle for the relationship between epileptiform bursts and electrographic seizures, two different kinds of epileptiform activities that arise in separate but mutually interactive locations. Moreover, although epileptic bursts can trigger electrographic seizures, their main effect may be to suppress seizures arising in their target areas. Thus, the interictal spikes that epileptiform bursts draw in EEG may have a suppressive effect on seizure discharges ([15], p. 380).

d) These two epileptogenic movements are interdependent and, at the same time, mutually antagonistic in such way that the strengthening of first one implies the weakening or even the disappearance of the second one, and vice versa [15] [16].

In the light of these pieces of information pointing to the physiological nature of some kinds of epileptic activities, we posed a second and more defiant hypothesis: the psychic automatisms termed HMAs would be physiological and they must be interpreted as expression of the cognitive cerebral function responsible of clairvoyant intuitions. We proposed to denominate this function hyperia [3] [4].

Along this same decade and half a great body of knowledge about neurogenesis has been accumulated [17]. Surprisingly, the explanations about the functioning of neuronal plasticity and the elucidations on functioning of 
hyperia contain so many similarities that both hypotheses seem true reflex each to other. This striking parallelism between hyperia and neurogenesis, and the consequent strong support that such similarity constitutes for our challenging hypothesis, is the main aim of this paper. We divide it in the next sections:

Section 2: Hypothesis of hyperia;

Section 3: Parallelisms between hyperia and neuronal plasticity;

Section 4: Discussion;

Section 5: Conclusion.

\section{Hypothesis of Hyperia}

There is much evidence indicating that two different and antagonic kinds of epileptogenic activities of physiological nature are present in certain cerebral areas. Thus, it is preferable term them hypersynchronic activities better than epileptic activities since this last denomination implies a pathological nature. Well, all collected information indicates that after an initial hypersynchrony it appears sometimes a second type of epileptogenic activity that could seems reactive and whose main purpose would be to regulate the intensity of the first one. We propose the first type to be called hyperia and to reserve the term epilepsy for the second type.

The term hyperia is derived from the Greek adverb hyper, a prefix meaning over, beyond the ordinary or normal [18]. Thus, hyperia means the excessiveness [19] implicit during this cerebral functioning mode: an excessive neuronal synchronization; an excessive alignment of consciousness; hyperesthesia of the experience, etc. We think that this substantive is useful to clearly separate and differentiate hyperic and epileptic activities.

Hyperia, as others cognitive brain functions, is largely hereditary and in this regard there are certain groups of people that show a strong inherited hyperic capacity, for example philosophers, scientists, artists, mystics, mental ill people, etc. Equally, as remaining cognitive functions, hyperia is also an educable activity and many people have learned to use the adequate stimuli, usually repetitive ones, in order to trigger these automatisms: twinkling lights, monotonous sounds, recurring melodies, repetitive mantras, rhythmic dances, etc.

Psychic experiences of hyperia always entail a sudden clairvoyant cognition accompanied frequently by telepathic conviction. The Merriam-Webster online dictionary defines clairvoyance [20] as an ability to communicate with dead people, to predict future events, or to know about things that you did not actually see happen or hear about. So, the term clairvoyance entails different paranormal phenomena, and clairvoyance and telepathy almost become synonyms.

Again, we will turn to déjà vu to understand better what we are trying to say. During this paramnesia the subject has the feeling of reliving a previously experienced scene, but feels completely unable to associate it with previous memories or experiences. Thus, the subject experiences it as something alien to his own mind and/or coming from other different mind. This interpretation of déjà vu as a telepathic phenomenon is more evident when this paramnesia is accompanied by cognition of events taking place at a distance, a fact that occurs with relative frequency [21].

Something similar can be said of the autoscopy, a peculiar kind of depersonalization that is also usually interpreted as a paranormal experience alien to the self mind [22]-[24].

The same occurs with the sudden fits of melancholic inhibition [25] or the opposite one of ecstatic exaltation [26]. These episodes, which correspond exactly to the psychopathological description of mania and melancholy, are experienced by the subject as something alien to their self mind. The phase of manic exaltation is often characterized by feelings of omnipotence and communion with the Absolute. Meanwhile, the melancholic phase is usually accompanied by delusional ideas of guilt and the consequent punishment attributed to an external mind, for example, a divine punishment.

This is even more evident in acute psychoses in which use to appear a delusional awareness, a phenomenon that Jaspers described in the following terms: "Patients possess knowledge of immense and universal happenings, sometimes without any trace of clear perceptual experience of them” ([7], p. 103). That is, these patients experience sudden and clairvoyant intuitions.

At this regard, we have found in our researches about HMAs striking and vivid descriptions of clairvoyant knowledge in numerous writings of renowned artists. For example, Aldous Huxley reports this delusional awareness, triggered by intake of mescaline, as follows:

The Beatific Vision, Sat Chit Ananda, Being-Awareness-Bliss, for the first time I understood, not on the verbal level, not by inchoate hints or at a distance, but precisely and completely what those prodigious syllables re- 
ferred to ([27], p. 5).

Hermann Hesse tells us a very similar experience, although now the triggering stimulus of clairvoyant cognition of the Absolute was a piece of music:

It was at a concert of lovely old music. After two or three notes of the piano the door was opened all of a sudden to the other world. I sped through heaven and saw God at work. I dropped all my defenses and was afraid of nothing in the world. I accepted all things and to all things I gave up my heart ([28], p. 19).

Finally, St. Ignatius of Loyola recounts in his autobiography the following case of multiple clairvoyant cognitions that seemed triggered by the light and acoustic stimuli that came after watching the riverbed:

One day he went to the Church of St Paul, about a mile away from Manresa. Near the road there is a stream, on the bank of which he sat, and gazed at the deep waters flowing by. While seated there, the eyes of his soul were opened. He did not have any special vision, but his mind was enlightened on many subjects, spiritual and intellectual. So clear was this knowledge that from that day everything appeared to him in a new light. Such was the abundance of this light in his mind that all the divine helps received, and all the knowledge acquired up to his sixty-second year, were not equal to it ([29], p. 57).

As we have explained just above, these clairvoyant experiences are present in many psychiatric disorders. In fact, all psychotic delusions entail this character of clairvoyance and/or telepathy. In all these irrefutable convictions the subject experiences an enlargement of self accompanied of telepathic certainty, a fact that is more evident in acute paranoid psychoses and in acute phases of paranoid schizophrenia (broadcasting thought, robbery of thought, echo of thought, etc.) and more diffuse in chronic psychoses in which megalomaniac ideas use to consist in experiences of self-reference and control by other minds (paranoia) or of fusion with Universal Mind (paraphrenia).

Scientific researches on these phenomena are often included in the field of parapsychology under the generic term psi phenomena [30]-[32] and although the results are inconclusive, their genesis seems related to the cerebral areas that we have described as more prone to hyperic hypersynchrony, concretely with hippocampal areas [33]-[35].

\section{Parallelism between Hyperia and Neuronal Plasticity}

The first fact taking our attention was the surprisingly parallelism existent between hyperic function and neuronal plasticity. Neuronal plasticity is the property that neurons have to build and to destroy some of their architectural elements in a constant way. The mechanism by which nervous cells build new structures is called long term potentiation (LTP), while long term depression (LTD) is the inverse mechanism by means of which neurons destroy or remove these new structures. These two mechanisms-LTP and LTD-are considered the basis of memories and of oblivions [36].

It has been much discussion about what are the roles of different glutamate receptors in these two processes, and although much controversy still exists on this topic, we can summarize all this information in three points:

1) LTP and LTD can be elicited by $\alpha$-amino-3-hydroxy-5-methyl-4-isoxazolepropionic acid receptor s (AMPAr) and N-methyl-D-aspartate receptors (NMDAr), although both activities are more evident and more widespread with the first type of receptors. But, curiously neuronal plasticity mediated by AMPAr requires a previous activation of NMDAr, which allows entry of $\mathrm{Ca}^{2+}$ in the postsynaptic neuron and, thus, the implementation of a number of molecular changes that determine an increase or decrease of AMPAr density [37].

2) Roughly speaking, we can apply these same statements to memory and to forgetting which are two active processes determined by LTP and LTD respectively [38].

3) Actually, at all central synapses AMPA and NMDA receptors form a functional synaptic unity in such way that presynaptically released glutamate coactives both types of receptors. This simultaneous activation of postsynaptic AMPAr and NMDAr arouses complexes and even contradictory responses, that is, sometimes producing an increase of AMPAr density and a decrease of NMDAr density, and other times vice versa [17].

If we pay attention we will note the existence of a strong parallelism between cerebral function that we have called hyperia and cerebral function termed neuroplasticity. Indeed, both functions involve:

1) The same cerebral areas, concretely the most prone to hypersynchronic functioning.

2) The same neuronal transmission. Indeed, hyperia and neuroplasticity are mediated by two complementary and at the same time opposed neurotransmitters: NMDA and AMPA activities, with a complex mechanism that is constantly rebalancing these two antagonistic forces [39]. Recent neurophysiological investigations suggest that this continuous rebalancing of NMDA and AMPA activities is related with the also constantly changing fo- 
cus of attention [40]-[43]. At this regard, hyperic phenomena are states in which, by means of an intense AMPA activation, attention is strongly focused on a sole experience occurring at this moment in the mind. This is what occurs, for example, during hyperic experiences triggered after have consumed ketamine or phencyclidine, two substances that antagonize NMDAr and, by this way, reinforce AMPA activity [44]. It is a well known fact that these two substances produces dissociative states and behaviors similar to schizophrenic-like psychoses [45] during which appear mental automatisms with the characteristic strong focusing of attention. A similar conclusion can be deduced of the study of Lovinger and others [46] with ethanol, a substance that inhibits strongly NMDA transmission but only weakly AMPA one.

3) These neuronal hypersynchronies are elicited in both cases by repetitive stimuli. This acute susceptibility of central nervous system to all repetitive stimuli should not be surprising since it is the way by means of which our brain learns and memorizes occurred experiences.

4) In both cases EEG shows similar shapes, currently termed action potentials and formerly usually denominated interictal spikes.

In sum, there are many data suggesting that the mechanisms used by the brain to elicit the hypersynchronic activity termed neuronal plasticity are the same used to produce hyperia. These similarities are so striking that we are inclined to think that hyperia is simply a concrete form of the numerous varieties of neuronal plasticity existing in our central nervous system such as neuronal plasticity occurring during sleep, during sexual activity, in any learning process, etc. This interpretation of hyperic function as a singular type of neuronal plasticity constitutes a new and strong argument in favor our very innovative hypothesis of hyperia as a physiological function.

\section{Discussion}

The hypothesis of hyperia implicates important consequences and modifications in the comprehension of different neuroscientific areas, which can be grouped in three sections:

A) Comprehension of paradoxical relations between epilepsy and psychoses;

B) Consequences that such hypothesis entails about current classification and diagnosis of psychiatric disorders;

C) Changes of hyperic hypotheses regarding therapy of psychiatric disorders.

A) Comprehension of paradoxical relations between epilepsy and psychoses

The hypothesis of hyperia let us to understand some neuroscientific questions regarding the contradictory relationship between epilepsy and psychoses that remain unexplained until now. Starr (summarizes this paradox in the next terms:

One of the great unresolved medical controversies of the twentieth century concerns the relationship between epilepsy and psychosis. Limbic structures are suspected of being intimately involved in the pathophysiology of both of these neurological conditions, yet more than a century medical thinkers have failed to agree upon whether these two common disorders are closely associated, unrelated, or mutually antagonistic to one another ([47], p. 160).

Indeed, on one hand, it is an undeniable fact the high comorbidity of epilepsy and psychoses. On the other hand, these two activities are incompatible simultaneously, as we can easily deduce from the next three facts:

1) The phenomenon termed forced normalization of EEG [48];

2) The often clinical observation that a generalized seizure terminates a state of acute psychosis [49];

3) The still effective treatment of psychoses with electro-convulsive therapy after eighty year of use [50].

This until present unsolved information on the relationship of epilepsy and psychoses is naturally explained by our hypothesis. Indeed epilepsy is to hyperia what firefighter's water is to fire of a conflagration: both them frequently appear together but they antagonistic and even incompatible at the same time.

Hypothesis of hyperia also helps to explain some other questions about epileptic and psychiatric overlapping, concretely some psychopharmacological aspects shared by these two matters:

1) Why are all anticonvulsant drugs, which initially were introduced in psychiatry as mood stabilizers, are resulting useful for more and more psychiatric disorders, concretely anxiety disorder [51], positive syndrome of schizophrenia and schizophrenic-like psychosis [52], and remarkably bipolar disorder [53] [54];

2) Why is there increasing evidence that the final effect that different psychotropic drugs have on the central nervous system is to decrease neuronal excitability? When we postulated the anticonvulsant role of antidepressant and antipsychotic drugs, nearly fifteen years ago [3], we were confronting the general position of psychiatry, which traditionally defended the proconvulsant role of these substances as could be read in the most used hand- 
books of psychiatry [55]. Since then, much new and strong support has appeared, confirming our innovative propose about the anticonvulsant effect of psychopharmacological drugs, namely:

a) Selective serotonin reuptake inhibitors [56]-[58];

b) Lithium [59]-[61];

c) Dual antidepressant: Not only modern ones [62] [63] but also classic tricyclic ones [64];

d) Antipsychotic drugs, as it is deduced from the increasing consistency of glutamate hypothesis of schizophrenia [65] [66] and also from the abundant information regarding the probable gabergic effect of these substances [67] [68].

B) Consequences that hypothesis of hyperia entails about current classification and diagnosis of psychiatric disorders

A second important consequence of hyperia comes from the major changes that such hypothesis entails about current classifications of psychiatric disorders. In effect, hyperia constitutes a singular and equal etio-pathogenic explanation for psychiatric symptoms currently attached to different disorders such as mania and/or melancholia (belonging to bipolar disorder), paranoid schizophrenia (belonging to schizophrenic disorders), crises of depersonalization (included in disorder of depersonalization), panic attacks (included in panic disorder), etc. The fact that all these clinical manifestations share the similar etiology, pathogenesis and treatment points to:

1) The loss of relevance of non-psychotic/psychotic duality as taxonomic criterion since mental automatisms of hyperia contain so much psychotic as non-psychotic manifestations and all they have the same genesis.

2) Conversely, negative/positive symptoms binomial acquires great taxonomic relevance. Indeed, from the hyperic perspective we can divide psychiatric disorders in two main groups:

a) On the one hand, psychiatric disorders with positive and/or productive manifestations that in advance are physiological and only become of pathological nature when they entail moral or social consequences with psychosocial deterioration [69] [70]. Thus, these mental disorders are interpreted as dimensional ones with their psychic manifestations going from normal to pathological.

b) On the other hand, a second group of clinical entities in which exist a pathogenic disturbance that determines the appearance of negative and/or defective symptoms. This second set would be constituted by categorical disorders such as mental retardations, dementias, autistic spectrum, and syndromes with predominant negative and defective cognitive symptoms. Consequently, positive syndrome of schizophrenia and negative syndrome of schizophrenia would be classified in different groups, being dimensional the first one and categorical the second one.

We think that this new taxonomic model, in which many psychic manifestations are interpreted as pathological only when they produce clear psychosocial consequences, supposes important advantages with respect to the current ICD-10 and DMS-5 models, concretely meeting the etiologic and pathogenic requirements of Research Domain Criteria (RDoC) to get a new diagnostic model in psychiatry [71].

C) Changes of hyperic hypotheses regarding therapy of psychiatric disorders

Finally, the third significant consequence of our hypothesis refers to the different therapeutic approach that from now on will need to be applied to mental manifestations of hyperia. Until now they were considered pathological and were treated as such. From now on, in principle, they do not need any therapy because they are expressions of a productive function of our brain. However, they have been considered for hundreds of years the expression of a disease, so it won't be possible to assimilate this new conception suddenly. Therefore, it is necessary to conduct psycho-educational efforts in order to this important conceptual change can be gradually assimilated. It will be necessary to teach young people experiencing these hyperic phenomena to become familiar with them. Families, teachers, and psycho-pedagogues also have to realize this new conception in order to help children and youngsters with intense manifestations of hyperia. The numerous advantages of this new approach can be summarized in one sentence: it is preferable to say to a child or teenager: "You are gifted with hyperia", than to tell him: "You have a mental or epileptic illness". This preventive task in order to avoid the psychiatrization of people with hyperic manifestations is one of the most important aims derived from hiperic hypothesis.

Finally, and still regarding the treatment of hyperic experiences, we consider necessary to add a last important detail: The superior efficacy of simultaneous treatment with psychopharmacological drugs and psychotherapy, a fact repeatedly evidenced over the years [72]-[74], is naturally consistent with hypothesis of hyperia since according it the desired modifications of neuronal neurotransmission can be achieved equally with physico-chemical stimuli than with psycho-emotional ones, being the most important that these stimuli have a repetitive character. 


\section{Conclusion}

There are clear evidences pointing to the physiological origin of mental automatisms appearing with phenomenological features of SPSs. We include all these phenomena into a cognitive function to which we propose term "hyperia". These automatic psychic experiences always imply convictions of clairvoyance and/or telepathy and they are generated by the same mechanisms used by our brain to produce the different varieties of neuronal plasticity.

\section{Declaration of Conflicting Interests}

The author declared no potential conflicts of interest with respect to the research, authorship, and/or publication of this article.

\section{References}

[1] Kinnier Wilson, S.A. (1928) Modern Problems in Neurology. Edward Arnold, London.

[2] Ey, H. (1954) Études Psychiatriques. Desclée de Brouwer, Paris.

[3] Álvarez, J. (2001) Neuronal Hypersyncronization, Creativity and Endogenous Psychoses. Medical Hypotheses, 56, 672-685. http://dx.doi.org/10.1054/mehy.2000.1269

[4] Alvarez-Rodriguez, J., Alvarez-Silva, S. and Alvarez-Silva, I. (2005) Epilepsy and Psychiatry: Automatic Psychic Paroxysms. Medical Hypotheses, 65, 671-675. http://dx.doi.org/10.1016/j.mehy.2005.03.030

[5] Alvarez-Rodriguez, J. (2014) Psychic Neuronal Hypersynchronies: A New Psychiatric Paradigm? Health, 6, 20892099. http://dx.doi.org/10.4236/health.2014.616242

[6] Devinsky, O. and Luciano, D. (1991) Psychic Phenomena in Partial Seizures. Seminars in Neurology, 11, 100-109. http://dx.doi.org/10.1055/s-2008-1041211

[7] Jaspers, K. (1997) General Psychopathology. The Johns Hopkins University Press, Baltimore and London.

[8] Beaumanoir, A., Gastaut, H. and Naquet, R. (1989) Reflex Seizures and Reflex Epilepsies. Editions Médicine et Hygiène, Paris.

[9] Critchley, M. and Henson, R.A. (1977) Music and the Brain. William Heinemann Medical Books Limited, London.

[10] Penman, J. and Becker, J. (2009) Religious Ecstatics, “Deep Listeners”, and Musical Emotion. Empirical Musicology Review, 4, 49-70.

[11] Pontius, A.A. and Wieser, H.G. (2004) Can Memories Kindle Nonconvulsive Behavioral Seizures in Humans? Case Report Exemplifying the “Limbic Psychotic Trigger Reaction”. Epilepsy \& Behavior, 5, 775-783. http://dx.doi.org/10.1016/j.yebeh.2004.05.013

[12] Schwartzkroin, P.A. (2007) Epilepsy: Models, Mechanisms and Concepts. Cambridge University Press, New York.

[13] Sengupta, A., Mahmoud, A., Tun, S.Z. and Goulding, P. (2010) Orgasm-Induced Seizures: Male Studied with Ictal Electroencephalography. Seizure, 19, 306-309. http://dx.doi.org/10.1016/j.seizure.2010.04.007

[14] Ozkara, C., Ozdemir, S., Yilmaz, A., Uzan, M., Yeni, N. and Ozmen, M. (2006) Orgasm-Induced Seizures: A Study of Six Patients. Epilepsia, 47, 193-197. http://dx.doi.org/10.1111/j.1528-1167.2006.00648.x

[15] Wilson, W.A. and Bragdon, A. (1993) Brain Slice Models for the Study of Seizures and Interictal Spikes. In: Schwartzkroin, P.A., Ed., Epilepsy: Models, Mechanisms and Concepts, Cambridge University Press, New York, 371-387. http://dx.doi.org/10.1017/CBO9780511663314.015

[16] Uva, L., Librizzi, L., Wendling, F. and De Curtis, M. (2005) Propagation Dynamics of Epileptiform Activity Acutely Induced by Bicuculline in the Hippocampal-Parahippocampal Region of the Isolated Guinea Pig Brain. Epilepsia, 46, 1914-1925. http://dx.doi.org/10.1111/j.1528-1167.2005.00342.x

[17] Traynelis, S.F., Wollmuth, L.P., McBrain, C.J., Meniti, F.S., Vance, K.M., Ogden, K.K., et al. (2010) Glutamate Receptor Ions Channels: Structure, Regulation, and Function. Pharmacological Reviews, 62, 405-496. http://dx.doi.org/10.1124/pr.109.002451

[18] Hyper (2013) The Oxford English Dictionary. Oxford University Press, Oxford.

[19] Excessiveness (2014) American Heritage Dictionary of the English Language. Houghton Mifflin Harcourt Publishing Company. http://www.thefreedictionary.com/excessiveness

[20] Clairvoyance (2015) http://Merriam-Webster.com http://www.merriam-webster.com/dictionary/clairvoyance

[21] Gerrans, P. (2014) Pathologies of Hyperfamiliarity in Dreams, Delusions and déjà vu. Frontiers in Psychology, 5, 97. 
http://dx.doi.org/10.3389/fpsyg.2014.00097

[22] Furlanetto, T., Bertone, C. and Becchio, C. (2013) The Bilocated Mind: New Perspectives on Self-Localization and Self-Identification. Frontiers in Human Neuroscience, 7, 71. http://dx.doi.org/10.3389/fnhum.2013.00071

[23] Occhionero, M. and Cicogna, P.C. (2011) Autoscopic Phenomena and One’s Own Body Representation in Dreams. Consciousness and Cognition, 20, 1009-1015. http://dx.doi.org/10.1016/j.concog.2011.01.004

[24] Brugger, P., Blanke, O., Regard, M., Bradford, D.T. and Landis, T. (2006) Polyopic Heautoscopy: Case Report and Review of the Literature. Cortex, 42, 666-674. http://dx.doi.org/10.1016/S0010-9452(08)70403-9

[25] Alvarez-Silva, I., Alvarez-Rodriguez, J., Alvarez-Silva, S., Perez-Echeverria, M.J. and Campayo-Martínez, A. (2007) Melancholic Major Depression and Epilepsy. Medical Hypotheses, 69, 1046-1053. http://dx.doi.org/10.1016/j.mehy.2007.01.088

[26] Picard, F. and Kurth, F. (2014) Ictal Alterations of Consciousness during Ecstatic Seizures. Epilepsy \& Behavior, 30, 58-61. http://dx.doi.org/10.1016/j.yebeh.2013.09.036

[27] Huxley, A. (1963) The Doors of Perception. Holt, Rinehart and Winston, Inc., Berlin.

[28] Hesse, H. (1963) Steppenwolf. Holt, Rinehart and Winston, Carls-bad. http://img0.liveinternet.ru/images/attach/c/0/3716/3716962_hermann_hesse_steppenwolf.pdf

[29] St. Ignatius of Loyola (1900) Autobiography. Benzinger Brothers, New York. http://www.gutenberg.org/files/24534/24534-h/24534-h.htm

[30] Noakes, R. (2014) Haunted Thoughts of the Careful Experimentalist: Psychical Research and the Troubles of Experimental Physics. Studies in History and Philosophy of Science Part C: Studies in History and Philosophy of Biological and Biomedical Sciences, 48, 46-56. http://dx.doi.org/10.1016/j.shpsc.2014.07.003

[31] Bobrow, R.S. (2011) Evidence for a Communal Consciousness. Explore, 7, 246-248. http://dx.doi.org/10.1016/j.explore.2011.04.001

[32] Pasricha, S.K. (2011) Relevance of Para-Psychology in Psychiatric Practice. Indian Journal of Psychiatry, 53, 4-8. http://dx.doi.org/10.4103/0019-5545.75544

[33] Persinger, M.A. and Saroka, K.S. (2012) Protracted Parahippocampal Activity Associated with Sean Harribance. International Journal of Yoga, 5, 140-145. http://dx.doi.org/10.4103/0973-6131.98238

[34] Venkatasubramanian, G., Jayakumar, P., Nagendra, H., Nagaraja, D., Deeptha, R. and Gangadhar, B. (2008) Investing Paranormal Phenomena: Functional Brain Imaging of Telepathy. International Journal of Yoga, 1, 66-71. http://dx.doi.org/10.4103/0973-6131.43543

[35] Rahey, S. (2004) Prescience as an Aura of Temporal Lobe Epilepsy. Epilepsia, 45, 982-984. http://dx.doi.org/10.1111/j.0013-9580.2004.68603.x

[36] Malenka, R.C. and Bear, M.F. (2004) LTP and LTD: An Ebarrassment of Riches. Neuron, 44, 5-21. http://dx.doi.org/10.1016/j.neuron.2004.09.012

[37] Rebola, N., Srikmuar, B.N. and Mulle, C. (2010) Activity-Dependent Synaptic Plasticity of NMDA Recepotors. The Journal of Physiology, 588, 93-99. http://dx.doi.org/10.1113/jphysiol.2009.179382

[38] Hard, O., Nader, K. and Wang, Y.T. (2013) GluA2-Dependent AMPA Receptor Endocytosis and the Decay of Early and Late Long-Term Potentiation: Possible Mechanisms for Forgetting of Short- and Long-Term Memories. Philosophical Transactions of the Royal Society B: Biological Sciences, 369, 20130141. http://dx.doi.org/10.1098/rstb.2013.0141

[39] Di Ciano, P. and Everitt, B.J. (2001) Dissociable Effects of Antagonism of NMDA and AMPA/KA Receptors in the Nucleus Accumbens Core and Shell on Cocaine-Seeking Behavior. Neuropsychopharmacology, 25, 341-360. http://dx.doi.org/10.1016/S0893-133X(01)00235-4

[40] Cottone, P., Imelo, A., Narayan, A.R., Kwak, J., Momaney, D. and Sbino, V. (2013) The Uncompetitive NMDA Receptor Antagonists Ketamine and Memantine Preferentially Increase the Choice for a Small, Immediate Reward in Low-Impulsive Rats. Psychopharmacology, 226, 127-138. http://dx.doi.org/10.1007/s00213-012-2898-3

[41] Pozzi, L., Baviera, M., Sachetti, G., Calcagno, E., Balducci, C., Invernizzi, R.W. and Carli, M. (2011) Attention Deficit Induced by Blockade of N-Methyl D-Aspartate Receptors in the Prefrontal Cortex Is Associated with Enhanced Glutamate Release and cAMP Response Element Binding Protein Phosphorylation: Role of Metabotropic Glutamate Receptors 2/3. Neuroscience, 176, 336-348. http://dx.doi.org/10.1016/j.neuroscience.2010.11.060

[42] Carli, N., Calcagno, E., Mainolfi, P., Mainini, E. and Invernizzi, R.W. (2011) Effects of Aripiprazole, Olanzapine, and Haloperidol in a Model of Cognitive Deficit of Schizophrenia in Rats: Relationship with Glutamate Release in the Medial Prefrontal Cortex. Psychopharmacholoy, 214, 639-652. http://dx.doi.org/10.1007/s00213-010-2065-7

[43] Greco, B., Invernizzi, R.W. and Carli, M. (2005) Phencyclidine-Induced Impairment in Attention and Response Control Depends on the Background Genotype of Mice: Reversal by the mGLU(2/3) Receptor Agonist LY379268. Psy- 
chopharmacology, 179, 68-77. http://dx.doi.org/10.1007/s00213-004-2127-9

[44] Moghaddam, B. and Javvit, D. (2012) From Revolution to Evolution: The Glutamate Hypothesis of Schizophrenia and Its Implication for Treatment. Neuropsychopharcalogy, 37, 4-15. http://dx.doi.org/10.1038/npp.2011.181

[45] Krystal, J.H., Karper, L.P., Seibyl, J.P., Freeman, G.K., Delaney, R., Bremner, J.D., et al. (1994) Subanesthetic Effects of the Noncompetitive NMDA Antagonist, Ketamine, in Humans. Psychotomimetic, Perceptual, Cognitive, and Neuroendocrine Responses. Archives of General Psychiatry, 51, 199-214. http://dx.doi.org/10.1001/archpsyc.1994.03950030035004

[46] Lovinger, D.M., White, G. and Weight, F.F. (1990) NMDA Receptor-Mediated Synaptic Excitation Selectively Inhibited by Ethanol in Hippocampal Slice from Adult Rat. The Journal of Neuroscience, 10, 1372-1379.

[47] Starr, M.S. (1996) The Role of Dopamine in Epilepsy. Synapse, 22, 159-194. http://dx.doi.org/10.1002/(SICI)1098-2396(199602)22:2<159::AID-SYN8>3.0.CO;2-C

[48] Wolf, P. (1991) Acute Behavioral Symptomatology at Disappearance of Epileptiform EEG Abnormality. Paradoxical or "Forced" Normalization. Advances in Neurology, 55, 127-142.

[49] Pollock, D.C. (1987) Models for Understanding the Antagonism between Seizures and Psychosis. Progress in NeuroPsychopharmacology and Biological Psychiatry, 11, 483-504.

[50] Finn, M. (1986) Convulsive Therapy and Epilepsy Research. In: Trimble, M.R. and Reynolds, E.H., Eds., What Is Epilepsy? Churchill Livingstone, Edinburgh, 217-228.

[51] Van Ameringen, M., Manzini, C., Pipe, B. and Benett, M. (2004) Antiepileptic Drugs in Treatment of Anxiety Disorders: Role in Therapy. Drugs, 64, 2199-2220. http://dx.doi.org/10.2165/00003495-200464190-00004

[52] Landmark, C.J. and Johannessen, S.I. (2010) New Antiepileptic Drugs in Neuropsychiatric Disorders. In: Ritchner, M.S., Ed., Brain Protection in Schizophrenia, Mood and Cognitive Disorders, Springer, New York, 485-504. http://dx.doi.org/10.1007/978-90-481-8553-5_16

[53] Mazza, M., Di Nicola, M., Della Marca, G., Janiri, L., Bria, P. and Mazza, S. (2007) Bipolar Disorder and Epilepsy: A Biridectional Relation? Neurobiological Underpinings, Current Hypotheses, and Future Research Directions. Neurocientist, 13, 392-404. http://dx.doi.org/10.1177/10738584070130041101

[54] Cookson, J. and Elliot, B. (2006) The Use of Anticonvulsants in the Aftermath of Mania. Journal of Psychopharmacology, 20, 23-30. http://dx.doi.org/10.1177/1359786806063073

[55] Mendez, M. (2000) Neuropsychiatric Aspects of Epilepsy. In: Sadock, B. and Sadock, V., Eds., Comprehensive Textbook of Psychiatry, Lippincott Williams \& Wilkins, Philadelphia, 261-273.

[56] Hong, L. and Bainbridge, J.L. (2014) Anticonvulsant Effects of SSRIs. Mental Health Clinician, 2, 19.

[57] Buchanan, G.F., Murray, N.M., Hajek, M.A. and Richerson, G.B. (2014) Serotonin Neurones Have Anti-Convulsant Effects and Reduce Seizure-Induced Mortality. The Journal of Physiology, 592, 4395-4410. http://dx.doi.org/10.1113/jphysiol.2014.277574

[58] Faingold, C.L. and Randall, M. (2013) Effects of Age, Sex, and Sertraline Administration on Seizure-Induced Respiratory Arrest in the DBA/1 Mouse Model of Sudden Unexpected Death in Epilepsy (SUDEP). Epilepsy \& Behavior, 28, 78-82. http://dx.doi.org/10.1016/j.yebeh.2013.04.003

[59] Ghasemi, M. and Dehpour, A.R. (2011) The NMDA Receptor/Nitric Oxide Pathway: A Target for the Therapeutic and Toxic Effects of Lithium. Trends in Pharmacological Sciences, 32, 420-434.

http://dx.doi.org/10.1016/j.tips.2011.03.006

[60] Bahremand, A., Ziai, P., Payandemehr, B., Rahimian, R., Amouzeqar, A., Khezrian, M., et al. (2011) Additive Anticonvulsant Effects of Agmatine and Lithium Chloride on Pentylenetetrazole-Induced Clonic Seizure in Mice: Involvement of $\alpha_{2}$-Adrenoceptor. European Journal of Pharmacology, 666, 93-99. http://dx.doi.org/10.1016/j.ejphar.2011.05.043

[61] Li, B., Zhang, S., Li, M., Zhang, H., Hertz, L. and Peng, L. (2009) Down-Regulation of GluK2 Kainate Receptor Expression by Chronic Treatment with Mood-Stabilizing Anti-Convulsants or Lithium in Cultured Astrocytes and Brain, but Not in Neurons. Neuropharmacology, 57, 375-385. http://dx.doi.org/10.1016/j.neuropharm.2009.07.004

[62] Borowicz, K.K., Golyaska, D., Luszczki, J.J. and Czuczwar, S.J. (2011) Effect of Acutely and Cronichally Administered Venlafaxine on the Anticonvulsant Action of Classical Antiepileptic Drugs in the Mouse Maximal Electroshock Model. European Journal of Pharmacology, 670, 114-120. http://dx.doi.org/10.1016/j.ejphar.2011.08.042

[63] Alper, K., Schwartz, K.A., Kilts, R.L. and Khan, A. (2007) Seizure Incidence in Psychopharmacological Clinical Trials: An Analysis of Food and Drug Administration (FDA) Summary Basis of Approval Reports. Biological Psychiatry, 62, 345-354. http://dx.doi.org/10.1016/j.biopsych.2006.09.023

[64] Jobe, P.C. and Browning, R.A. (2005) The Serotonergic and Noradrenergic Effects of Antidepressant Drugs Are Anticonvulsant, Not Proconvulsant. Epilepsy \& Behavior, 7, 602-619. http://dx.doi.org/10.1016/j.yebeh.2005.07.014 
[65] Coyle, J.T. (1996) The Glutamatergic Dysfunction Hypothesis for Schizophrenia. Harvard Review of Psychiatry, 3, 241-253. http://dx.doi.org/10.3109/10673229609017192

[66] Kim, J.S., Kornhuber, H.H., Schmid-Birgk, W. and Holzmüller, B. (1980) Low Cerebral Fluid Glutamate in Schizophrenic Patients and a New Hypothesis on Schizopgrenia. Neuroscience Letters, 20, 379-382. http://dx.doi.org/10.1016/0304-3940(80)90178-0

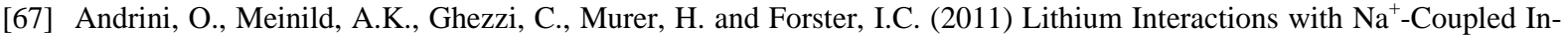
organic Phosphate Cotransporters: Insights into the Mechanism of Sequential Cation Binding. American Journal of Physiology_Cell Physiology, 302, C539-C554. http://dx.doi.org/10.1152/ajpcell.00364.2011

[68] Zhou, Y., Zomot, E. and Kanner, B.I. (2006) Identification of a Lithium Interaction Site in the Gamma-Aminobutyric (GABA) Transporter GAT.1. The Journal of Biological Chemistry, 281, 22092-22099. http://dx.doi.org/10.1074/jbc.M602319200

[69] Fuldford, K.W. (2011) Neuroscience and Values: A Case Study Illustrating Developments in Policy, Training and Research in the UK and Internationally. Mens Sana Monographs, 9, 79-92. http://dx.doi.org/10.4103/0973-1229.77428

[70] Kinghorn, W.A. (2011) Whose Disorder?: A Constructive MacIntyrean Critique of Psychiatric Nosology. Journal of Medicine and Philosophy, 36, 187-205. http://dx.doi.org/10.1093/jmp/jhr006

[71] Sanislow, C.A., Pine, D.S., Quinn, K.J., Kozak, M.J., Garvey, M.A., Heinssen, R.K., Wang, P.S. and Cuthbert, B.N. (2010) Developing Constructs for Psychopathology Research: Research Domain Criteria. Journal of Abnormal Psychology, 119, 631-639. http://dx.doi.org/10.1037/a0020909

[72] Keller, R.C., Ciu, W.T., Keller, M.B., McCullough, J.P., Klein, D.N., Amow, B., Dunner, D.L., Gelenberg, A.J., et al. (2000) A Comparison of Nefazodone, the Cognitive Behavioral-Analysis System of Psychotherapy, and Their Combination for the Treatment of Chronic Depression. The New England Journal of Medicine, 342, 1462-1470. http://dx.doi.org/10.1056/NEJM200005183422001

[73] Cuijpers, P., Dekker, J., Hollon, S.D. and Andersson, G. (2009) Adding Psychotherapy to Pharmacotherapy in the Treatment of Depressive Disorders in Adults: A Meta-Analysis. Journal of Clinical Psychiatry, 70, 1219-1229. http://dx.doi.org/10.4088/JCP.09r05021

[74] Zobel, I., Kech, S., van Calker, D., Dykierek, P., Berger, M., Schneibel, R. and Schramm, E. (2011) Long-Term Effect of Combined Interpersonal Psychotherapy and Pharmacotherapy in a Randomized Trial of Depressed Patients. Acta Psychiatrica Scandinavica, 123, 276-282. http://dx.doi.org/10.1111/j.1600-0447.2010.01671.x 